\title{
Marcas intertextuais na canção Velha roupa colorida, de Belchior
}

\author{
Antonia Sergiana Tavares de Oliveira" \\ Maria Margarete Fernandes de Sousa" \\ Francisco de Freitas Leite $e^{* * *}$
}

\section{Resumo}

Este trabalho tem como objetivo analisar as marcas intertextuais na canção Velha roupa colorida, de Belchior, e demonstrar como essa intertextualidade se manifesta por meio das relações de copresença e como o reconhecimento dessas ocorrências intertextuais contribui para a construção de sentidos do texto por parte do leitor/ouvinte. A abordagem teórica é fundamentada na proposta de Genette (2010), Piègay-Gros (2010) e Cavalcante e Brito (2011) e apoia-se também na perspectiva de Koch; Bentes e Cavalcante (2012), Koch (2014) e Costa (2012). A intertextualidade se faz presente na maioria das composições musicais de Belchior, chegando a ser uma das características de sua obra; no entanto, dado o escopo deste artigo, a análise foca apenas uma canção que atende satisfatoriamente ao propósito deste trabalho. A conclusão destaca que as ocorrências intertextuais, como citações, referências e alusão, contribuem sobremaneira para a construção do sentido do texto da canção em análise.

Palavras-chave: Intertextualidade. Construção de sentidos. Canção. Belchior.
Doutoranda em Linguística pelo Programa de Pós-Graduação em Linguística - DINTER UFC/URCA. Mestra em Ciências da Educação pela Universidade Lusófona de Humanidades e Tecnologias - Portugal (2014), com especialização em Educação, Desenvolvimento e Políticas Educativas pela Faculdade Nossa Senhora de Lourdes (2011), especialização em Literatura Brasileira (2001) e graduação em Letras - Língua Portuguesa pela Universidade Regional do Cariri (1999). Atualmente, é professora assistente $\mathrm{V}$ da Universidade Regional do Cariri. E-mail:serginha.to@bol.com.br

** Graduada em Letras pela Universidade Estadual do Ceará (1983), em Pedagogia pela Universidade de Fortaleza (1989), Mestra em Linguística pela Universidade Federal do Ceará (1998) e Doutora em Linguística pela Universidade Federal de Pernambuco (2005). É professora Associada, nível II, da Universidade Federal do Ceará e Coordenadora do Grupo de Pesquisa Gêneros: Estudos Teóricos e Metodológicos - GETEME/UFC. E-mail:margarete.ufc@gmail.com

**** Doutor em Linguística (Proling/UFPB - 2014), mestre em Linguística (Proling/UFPB - 2009), especialista em Ensino de Língua Portuguesa (Urca - 1999) e graduado em Letras (Urca - 1998). Concluiu estágio pós-doutoral junto ao PPGL-UFC (2015) na linha de pesquisa de Linguística Aplicada. Atualmente é professor adjunto $\mathrm{J}$ da Universidade Regional do Cariri-Urca, coordenador operacional do Dinter em Linguística (UFC/Urca), pesquisador do Núcleo de Estudos de Teoria Linguística e Literária - Netlli, pesquisador do Grupo de Pesquisas em Estudos Clássicos e Linguísticos - Grec, editor-geral da Miguilim - Revista Eletrônica do Netlli (Qualis/ Capes B2) e editor-adjunto da Macabéa - Revista Eletrônica do Netlli (Qualis/Capes B2). E-mail: freitas_leite@ hotmail.com

\footnotetext{
Data de submissão: jul. 2017 - Data de aceite: set. 2017 http://dx.doi.org/10.5335/rdes.v13i3.7272
} 


\section{Introdução}

Com o desenvolvimento e a expansão das novas mídias, o interesse dos pesquisadores pelo tema da intertextualidade tem se alargado cada vez mais, diante das infinitas possibilidades de uso dos textos e da interação entre as suas diferentes modalidades. É um tema que pode ser estudado pelas mais diferentes áreas da Linguística e da Literatura, portanto, assume as mais diferentes perspectivas dependendo da abordagem teórica empregada.

Neste trabalho, adotamos a perspectiva teórica da Linguística Textual e a concepção de texto do Dialogismo bakhtiniano, segundo a qual o discurso é essencialmente dialógico, já que todo enunciado se constitui como réplica de outros, numa relação de aliança ou confronto (BAKHTIN/VOLOCHÍNOV, 2004). Assim, para Koch,

[...] todo texto é um objeto heterogêneo, que revela uma relação radical de seu interior com seu exterior; e, desse exterior, fazem parte outro textos que lhe dão origem, que o predeterminam, com os quais dialoga, que retoma, a que alude ou a que se opõe (2014, p. 59).

O fenômeno da intertextualidade será estudado a partir dessa concepção de texto, entendida, portanto, como a relação que um texto estabelece com outros textos e que pode manifestar-se de diferentes maneiras.

Concordamos com Van Dijk (2008) acerca de que a intertextualidade pode representar uma importante condição para a compreensão e também para a apropriação do discurso; e, utilizando a metáfora de Bazerman (2011), de que criamos os nossos textos a partir do "oceano de textos" anteriores que estão a nossa volta e que compreendemos os textos dos outros dentro desse mesmo oceano, podemos entender melhor a afirmação de Ingedore Koch:

Todo texto possui apenas uma pequena superfície exposta e uma imensa área subjacente. Para se chegar às profundezas do implícito e dele extrair um sentido, faz-se necessário o recurso a vários sistemas de conhecimento e a ativação de processos e estratégias cognitivas e interacionais $(\mathrm{KOCH}$, 2014, p. 30).

Iremos trabalhar com o gênero canção, considerando a perspectiva de gêneros de discurso proposta por Bakhtin (2003), para quem gêneros são tipos relativamente estáveis de enunciados que se elaboram no interior de cada esfera da atividade humana e que são atualizados a cada nova enunciação.

A canção é considerada um gênero híbrido, de caráter intersemiótico, porque, segundo Costa (2012), é o resultado da conjugação de dois tipos de linguagens: a materialidade verbal (o texto) e a materialidade musical (rítmica e melódica). Para este artigo, selecionamos a canção Velha roupa colorida, devido à constatação da presença de significativas ocorrências intertextuais em seus versos.

A presença do intertexto é identificável na maioria das canções de Belchior, chegando a ser uma característica marcante de sua produção musical. No 
entanto, dado o escopo deste artigo, optamos por analisar apenas a canção Velha roupa colorida, que, aqui, representará as demais e na qual demonstraremos as marcas de intertextualidade, categoria linguística que se configura foco deste estudo, a partir das relações de copresença: citação, referência e alusão.

A seguir, explicitaremos o referencial teórico, para melhor entendimento da nossa proposta de estudo e suporte teórico de análise.

\section{Intertextualidade}

Questões como cópia, influência e imitação são temas debatidos desde a antiguidade clássica. Podemos ver referência a essa temática já nos Diálogos de Platão (1993); de forma que isso nos leva a pensar que essa é uma questão que acompanha a evolução da escrita e, consequentemente, da literatura.

A noção de comparação entre obras surge inicialmente nos estudos literários a partir da identificação numa obra ou num autor de ressonâncias de outras obras e autores, sugerindo parentescos, afinidades ou inter-relações. No entanto, o termo intertextualidade será utilizado pela primeira vez pela crítica literária Julia Kristeva, só na década de 1960, embora a abordagem teórica sobre a ideia expressa pela intertextualidade tenha se iniciado com os estudos de Bakhtin sobre o dialogismo, segundo o qual todo "enunciado é um elo na corrente completamente organizada de outros discursos" (2003, p. 272).
De acordo com essa ideia expressa pelo dialogismo bakhtiniano, todo texto estabelece uma relação com outros, à medida que o discurso materializado por um texto será sempre permeado pelo discurso de outrem.

Na esteira de Bakhtin (2003), Júlia Kristeva, portanto, propõe que um texto é um conjunto de enunciados, tomados de outros textos, que se cruzam e se relacionam ou, em outras palavras, diz Kristeva que "todo texto se constrói como mosaico de citações, todo texto é absorção e transformação de um em outro texto" (1974, p. 64).

Nessa perspectiva, a intertextualidade seria inerente ao texto, ou nas palavras de Koch, Bentes e Cavalcante (2012), constitutiva de todo e qualquer discurso. Nesse caso, a relação entre dois textos, pode se tornar um objeto de difícil identificação ou percepção, por estar diluído por todo o texto, ou ainda, a partir dele. Segundo Cavalcante e Brito, "esta concepção elastece de tal modo a visão de intertextualidade que, sendo constitutiva, ela não precisa ser evidenciada" (2011, p. 261). Por outro viés, em alguns casos, essa relação entre textos fica bastante evidente. Sendo assim, Koch, Bentes e Cavalcante (2012) estabeleceram duas grandes categorias de intertextualidade: a intertextualidade em sentido amplo (lato sensu) e a intertextualidade em sentido restrito (stricto sensu).

A intertextualidade em sentido amplo aproxima-se da ideia de intertextualidade proposta por Kristeva (1974), considerada como necessária para a existência 
de qualquer discurso. Para Koch, Bentes e Cavalcante, as ligações que podem ser estabelecidas entre os textos não ocorrem apenas por meio de enunciados isolados, mas por intermédio de "modelos gerais e/ou abstratos de produção e recepção de textos/discursos" (BAUMAN; BRIGGS, 1995 apud KOCH; BENTES; CAVALCANTE, 2012, p. 85). A intertextualidade em sentido restrito, segundo as mesmas autoras, ocorre quando um texto está inserido em outro texto ou, em outras palavras, quando é necessário que o texto remeta a outros textos ou fragmentos de textos, efetivamente produzidos, com os quais se estabelece alguma forma de relação e pode ser de quatro tipos: intertextualidade temática, estilística, explícita e implícita.

Interessa-nos para o nosso objeto de estudo, nesse caso, a intertextualidade em sentido restrito (stricto sensu), por apontar o tipo de inter-relação de sentido que entendemos existir no material que analisamos. No entanto, as subcategorias propostas pelas autoras (intertextualidade temática, estilística, explícita e implícita) não serão consideradas, já que optamos pela abordagem teórica apresentada por Genette (2010), Piègay-Gros (2010) e Cavalcante e Brito (2011).

Partiremos do conceito genettiano de transtextualidade. Depois situaremos as abordagens teóricas de Piègay-Gros e Cavalcante e Brito para, assim, aprofundar e direcionar para o nosso propósito que é o estudo das marcas intertextuais por meio da copresença.
Para Genette os diálogos entre os textos configuram-se como relações de transtextualidade, definida como "tudo que coloca um texto em relação, manifesta ou secreta, com outros textos" (2010, p. 07). Essas relações transtextuais subdividem-se em cinco tipos:

- Intertextualidade - presença efetiva de um texto em outro, com ou sem referência (citação, plágio, alusão etc.).

- Paratextualidade - constituída pela relação, geralmente menos explícita e mais distante, entre dois textos (título, subtítulo, intertítulos, prefácios, posfácios, etc.).

- Metatextualidade - a relação que une um texto a outro texto do qual ele fala, sem necessariamente citá-lo (convocá-lo), até mesmo, em último caso, sem nomeá-lo (crítica literária).

- Hipertextualidade - toda relação que une um texto B (chamado de hipertexto) a um texto anterior $\mathrm{A}$ ( $h i$ potexto) do qual ele se origina de uma forma que não seja a do comentário.

- Arquitextualidade - conjunto de categorias gerais ou transcendentes ao texto (tipos de discurso, gêneros literários) de caráter taxionômico.

Embora não nos alonguemos na discussão desses itens, é conveniente destacar que consideramos o conjunto deles responsáveis pela composição/tessitura da materialidade textual, em consonância, óbvio, com as demais estratégias de constituição dos sentidos do texto ${ }^{1}$. 
Dos cinco tipos de transtextualidade reconhecidos pelo autor, iremos nos centrar no primeiro tipo: a intertextualidade, que Genette (2010) caracterizou de forma bem restritiva, como a presença de um texto em outro, ou seja, pela inserção efetiva de um texto em outro. $\mathrm{O}$ autor dividiu essa relação em três subtipos: a citação, forma mais explícita e mais literal de intertextualidade; o plágio, forma menos explícita e menos canônica, mas ainda literal, e a alusão, a forma menos explicita e menos literal, um enunciado cuja compreensão plena supõe a percepção de uma relação entre ele e um outro, ao qual necessariamente uma de suas inflexões remete.

Como já dito, os estudos de Genette (2010) foram retomados e rediscutidos por Piègay-Gros (2010). A autora incorporou o que Genette (2010) havia chamado de hipertextualidade (toda relação que une um texto $\mathrm{B}$ a um texto anterior A), ao conceito de intertextualidade, com uma nova nomenclatura: relações por derivação.

Quanto à relação por copresença, além dos três subtipos proposto por Genette e já mencionados, a autora acrescenta um: a referência, caracterizada como a remissão que o autor faz a um texto sem, no entanto, citá-lo diretamente. Dessa forma, de acordo com a classificação proposta por Piègay-Gros (2010) temos o Quadro 1.
Quadro 1 - Relações intertextuais

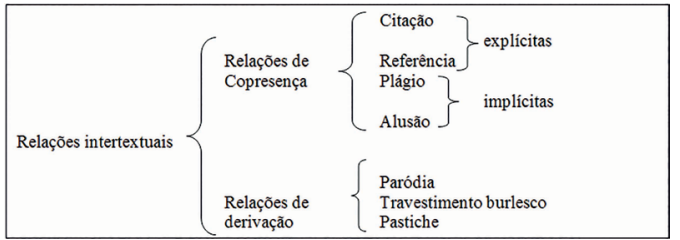

Fonte: adaptado de Piègay-Gros (2010).

Como o que nos interessa são as relações intertextuais por copresença, são nelas que centraremos nossa atenção. Como visto, a autora propõe quatro tipos de relações de intertextualidade por copresença: citação, referência, plágio e alusão, considerando as duas primeiras explícitas e as outras duas implícitas.

Segundo a autora, a intertextualidade explícita se caracteriza pela menção ao texto-fonte ou marcação do intertexto por meio de um código tipográfico (aspas, grifo, negrito, itálico). Nesse caso, o texto seria claramente demarcado. Já a intertextualidade implícita se caracteriza pela não assinalação do intertexto, cabendo ao leitor/ouvinte identificar a sua presença pela ativação de seu conhecimento prévio.

De acordo com Cavalcante e Brito (2011) a intertextualidade por copresença apresenta-se numa escalaridade que varia do mais alto grau de explicitude, quando é indicada por um código tipográfico (a citação), passando por graus medianos, como nas menções a títulos de obras, a autores, a trechos não aspeados nem italicizados (referência), até chegar àquilo que os autores consideram como 0 mais completo grau de implicitude, quando apenas se alude a outro texto (alusão). 
Quanto ao plágio, Cavalcante e Brito (2011) questionam se esse deveria figurar entre as relações de copresença, já que, para elas, ele deriva um novo texto, imitado em maior ou menor extensão. Além disso, o próprio autor do texto tem o propósito de dissimular a autoria do trecho plagiado. Concordamos com o questionamento das autoras, já que no nosso entendimento, o texto plagiado não se caracteriza pela presença de um texto em outro, mas na formação de um novo texto; de forma que, para nossa análise, seguimos a ideia de Cavalcante e Brito (2011) e não consideraramos o plágio, ficando o quadro das relações copresenciais da seguinte forma:

\section{CITAÇÃO - REFERÊNCIA - ALUSÃO}

Diante do exposto, iremos nos concentrar na citação, na referência e na alusão, enquanto formas de intertextualidade copresencial, as quais detalharemos a seguir.

\section{a) Citação}

Para Genette (2010) a citação é considerada a manifestação mais explícita e mais literal de intertextualidade, já que deixa claro para o leitor que houve empréstimo de um texto em outro texto. Por essa razão, segundo Compagnon (1979 apud PIÈGAY-GROS, 2010, p. 220), a citação estaria, dentro de uma escala, no "grau zero" de intertextualidade, ou seja, sendo a citação muito clara, bastante explícita e evidente, ela se mostra no texto abertamente, isto é, sem necessitar de uma maior sagacidade do leitor em reconhecer o intertexto.

Para Paulino, Walty e Cury (1995) a citação é um tipo de intertexto que utiliza trechos de outros textos de forma direta transcrevendo as palavras do texto de origem entre aspas duplas, normalmente acompanhada pelo nome do autor, ou indireta em que o autor utiliza as suas próprias palavras, mas sem abandonar as ideias do texto original. Geralmente, a citação é utilizada para fundamentar um texto utilizando textos de outros autores já reconhecidos ou legitimados com o intento de atribuir maior credibilidade ao discurso recém produzido. Porém, às vezes, a citação é utilizada não para confirmar um ponto de vista, mas também para refutá-lo, através da contra-argumentação. A esse processo, Charaudeau e Maingueneau (2008) denominam de citação com valor de captação e subversão, respectivamente. Não abordaremos esse processo em nosssa análise, de forma que não nos alongaremos nessa questão.

A citação também pode assumir função apenas ornamentativa. Esse recurso é utilizado principalmente em textos literário. Piègay-Gros (2010) diz, no entanto, que a citação pode exceder em muito as funções tradicionais que lhe são atribuídas, a autoridade e a ornamentação. No contexto da obra literária, por exemplo, uma citação bem escolhida pode ressignificar o texto desde que tenhamos ciência dos laços que se interpõem entre o texto 
citado e o citante, como também entre as diferentes ocorrências de um mesmo texto e entre os diversos textos citados.
Vejamos um exemplo de citação no poema $O$ mundo de Deus, do poeta Mário Quintana:

O Mundo de Deus

Aquele astronauta americano que anunciou ter encontrado Deus na lua é no fim de contas menos simplório do que os primeiros astronautas russos, os quais declararam, ao voltar, não terem visto Deus no céu.

Porque, se Deus é paz e paz é silêncio, afinal, deve Ele estar mesmo muito mais na lua do que nas metrópoles terrenas. $\mathrm{E}$, pelo que me toca, a verdade é que nunca pude esquecer estas palavras de um personagem de Balzac:

“O deserto é Deus sem os homens" (QUINTANA, 1973, p. 53, grifo nosso).

No poema, a citação está evidenciada pela menção ao nome do autor (Balzac) e pela marcação do intertexto entre aspas dupla. O texto com o qual o poeta estabelece relação é o conto Uma paixão no deserto, de Honoré de Balzac (1976), publicado em 1837, que conta a história de fuga e sobrevivência de um soldado francês que havia sido capturado por berberes no norte da África. O soldado, perdido no deserto, acha refúgio em uma gruta e consegue domesticar uma pantera com quem vive em miraculosa harmonia. A partir desse momento, o deserto passa a exercer nele uma espécie de fascinação e respeito, apesar da tensão e incerteza em que vive, pois nele encontrara o improvável, o mistério. Um dia, contudo, um gesto brusco lhe dá a impressão de que o animal vai devorá-lo e ele o apunhala. Ele se apercebe tardiamente de que o gesto era um sinal de afeição da parte do animal. Em seguida é encontrado pela tropa francesa e volta para a civilização. Muito tempo depois, já aposentado, ao relatar essa experiência a um interlocutor, esse pede para que $o$ soldado se explique melhor sobre o que sentia no deserto, ao que ele responde, concluindo a narrativa: "o deserto é Deus sem os homens".

Quando estabelecemos a relação entre o texto citante (o poema) e a obra citada (Uma paixão no deserto, de Balzac) o sentido do texto é inquestionavelmente ampliado já que vemos no conto, por meio da vivência do personagem no deserto, que o sentido de deserto comumente depreendido como o locus da inospitalidade e da falta absoluta de tudo que constuti a vida, é totalmente ressignificado, o que ajuda a construir o sentido global do poema. 
b) Referência

A referência também é considerada uma forma explícita de intertextualidade, já que o autor faz uma menção direta a um determinado texto, possibilitando o leitor fazer uma associação com o texto indicado. Porém, ao contrário da citação, como afirma Piègay-Gros (2010), a referência não expõe o outro texto ao qual remete o leitor, ou seja, ela estabelece uma relação in absentia, uma vez que se remete ao texto, sem citá-lo literalmente.

Koch, Bentes e Cavalcante (2012) questionaram essa assertiva ao afirma- rem que, se não há citação literal, a referência deveria ser tomada como um caso de alusão, a qual se caracteriza pela implicitude da referência do texto. Sendo assim, as autoras estabeleceram o seguinte critério, o qual adotamos: para conservar a referência como estratégia explícita de copresença, devemos considerá-la como uma menção direta ou a entidades do texto ou ao texto como um todo, ou seja, é necessário que haja a remissão direta aos personagens, autor e texto.

Vejamos como exemplo um fragmento da canção Retórica sentimental, de Belchior:

Que em matéria de palmeira ainda tem o buriti perdido.

Símbolo de nossa adolescência,

Signo de nossa inocência índia, sangue tupi.

E por falar no sabiá, o poeta Gonçalves Dias é que sabia... Sabe lá se não queria

Uma Europa bananeira (BELCHIOR, 1979, grifo nosso).

A referência dá ao leitor uma espécie de indicação explícita do que ele deve buscar na sua memória discursiva, pois remete-o a um texto mesmo sem citá-lo literalmente. No caso da canção exemplificada, Belchior faz uma referência ao poeta Gonçalves Dias e seu poema Canção do exílio mesmo sem citar o poema, mas apenas mencionando seu autor e duas palavras recorrente em seus versos: palmeira e sabiá. De posse dessa informação, a leitura do texto será acrescida de um novo significado.

\section{c) Alusão}

Para Genette (2010), a alusão é a forma menos explícita de intertextualidade, já que a remissão que faz a outro texto é de forma indireta. Corroborando essa ideia, Piègay-Gros diz que a alusão supõe, com efeito, que o leitor possa compreender nas entrelinhas o que o autor deseja sugerir-lhe sem expressar isso diretamente, "já que ela se baseia num jogo de palavras, aparece, de repente, como um elemento lúdico, um tipo de 
piscar de olhos divertido, dirigido ao leitor" (2010, p. 227).

Cavalcante e Brito (2011) dizem que aludir é realizar uma espécie de referenciação indireta, ao contrário do processo intertextual da referência, em que se remete diretamente a uma entidade.

Mais do que qualquer outra forma de intertextualidade por copresença, a alusão é a forma que mais precisa acionar o conhecimento prévio de leitor, já que recorre para a sua memória, ao supor que ele possa compreender nas entrelinhas o que o autor deseja sugerir-lhe sem expressar diretamente.

Piègay-Gros (2010) alerta para o fato de que a alusão solicita a memória e a inteligência do leitor sem haver a quebra da continuidade do texto. Vejamos nos fragmentos do poema Motivo, de Cecília Meirelles e da canção $O$ ciúme, de Caetano Veloso:

\section{Motivo}

Eu canto porque o instante existe e a minha vida está completa.

Não sou alegre nem sou triste: sou poeta (MEIRELES, 1994, p. 86, grifo nosso).

O ciúme

O ciúme lançou sua flecha preta

$\mathrm{E}$ se viu ferido justo na garganta

Que nem alegre nem triste nem poeta

Entre Petrolina e Juazeiro canta (VELOSO, 1987, grifo nosso).

A canção faz uma alusão ao poema através do verso: "Que nem alegre, nem triste, nem poeta" ao retomar os versos de Cecília Meireles: "Não sou alegre nem sou triste: / sou poeta". No poema, os versos indicam a plenitude em que se encontra o eu-lírico, ao sugerir que o poeta é um ser dotado de completude, já na canção, ao expressar que não é poeta, o eu-lírico indica que, apesar de não ser alegre nem triste, não consegue viver em plenitude já que é atormentado pela flecha negra do ciúme. Conhecendo o texto fonte, aquele trecho da canção adquire um sentido bem mais amplo.

Piègay-Gros (2010) enfatiza que a alusão pode ultrapassar, em muito, o campo da intertextualidade, já que pode remeter o leitor não apenas a outros textos, mas também à história, à mitologia, à opinião ou aos costumes. Portanto, nem toda alusão se caracteriza como intertextual, mas apenas aquela que faz referência a um texto específico. Assim também pensam Koch, Bentes e Cavalcante (2012) ao defender que 
nem toda remissão direta ou indireta a um conhecimento compartilhado pelos participantes da comunicação deva ser considerada como intertextual em sentido estrito, mas só aquela que se configure como um diálogo entre textos efetivamente produzidos.

Cavalcante e Brito (2011) denominam esse tipo de alusão mais genérica de alusão interdiscursiva que se caracteriza pela remissão à palavra do exterior discursivo, por meio de jogos de palavras, implicitações, disfarces, etc. Para nossa análise, consideraremos como intertextualidade em sentido estrito, apenas textos efetivamente produzidos e relacionados à materialidade escrita, falada e visual.

\section{Ocorrências intertextuais por copresença na canção Velha roupa colorida, de Belchior}

Antes de apresentarmos a análise, achamos pertinente situar resumidamente o autor e sua obra, contextualizando a canção Velha roupa colorida e suas condições de produção.

Antônio Carlos Gomes Belchior Fontenelle Fernandes, conhecido apenas como Belchior, nasceu em Sobral-CE, em 26 de outubro de 1946 e faleceu em Santa Cruz do Sul-RS, em 30 de abril de 2017. Durante sua infância em Sobral, foi cantador de feira e poeta repentista. No ano de 1962, mudou-se para Forta- leza, onde estudou Filosofia e Humanidades. Começou a estudar Medicina, mas abandonou o curso no quarto ano, em 1971, para dedicar-se à carreira artística. Nesse mesmo ano, vai para o Rio de Janeiro, onde vence o IV Festival Universitário de Música Brasileira, promovido pela TV Tupi, com a canção $N a$ hora do almoço. No ano seguinte, 1972, Elis Regina grava a canção Mucuripe, abrindo-lhe as portas para o reconhecimento nacional. Esteve ligado também a um grupo de jovens compositores e músicos, como Fagner, Ednardo, Rodger Rogério, Teti, entre outros, conhecidos como o Pessoal do Ceará.

Em 1974, lança seu primeiro LP, A palo seco. Seu último disco inédito, Bahiuno, foi lançado em 1993. Sua discografia completa consta de 22 álbuns, com mais de 300 composições. Além da música, ele se dedicava à pintura, à caricatura e ao desenho. A fonte consultada para os dados acima foi o Dicionário Cravo Albin da Música Popular Brasileira (2002).

A canção Velha roupa colorida foi lançada no álbum Alucinação em 1976, em um contexto de repressão e sensura ao direito de livre expressão, imposto pela Ditadura Militar ${ }^{2}$. Esse álbum consolidou-o no cenário musical brasileiro e nele estão alguns dos seus maiores sucessos, como Apenas um rapaz latino-americano, Como nossos pais, A palo seco e Fotografia 3x4.

Optamos por trabalhar apenas com a canção já referida, pela quantidade de 
ocorrências intertextuais por copresença encontrada em seus versos, as quais consideramos satisfatórias para o que propomos demonstrar. No entanto, vale ressaltar que a intertextualidade está presente na maioria de suas composições musicais, sendo esta, portanto, uma característica marcante da sua obra.

Observemos a canção Velha roupa colorida, que será analisada em seus aspectos intertextuais de construção de sentidos.

\section{VELHA ROUPA COLORIDA}

( 01 ) Você não sente, não vê

( 02 ) Mas eu não posso deixar de dizer, meu amigo

( 03 ) Que uma nova mudança em breve vai acontecer

( 04 ) O que há algum tempo era novo, jovem

( 05 ) Hoje é antigo

( 06 ) E precisamos todos rejuvenescer

( 07 ) Nunca mais teu pai falou: "She's leaving home"

( 08 ) E meteu o pé na estrada "like a Rolling Stone"

( 09 ) Nunca mais você buscou sua menina

( 10 ) Para correr no seu carro, loucura, chiclete e som

( 11 ) Nunca mais você saiu à rua em grupo reunido

( 12 ) $\mathrm{O}$ dedo em $\mathrm{V}$, cabelo ao vento

( 13 ) Amor e flor (que é do cartaz?)

( 14 ) No presente a mente, o corpo é diferente

( 15 ) E o passado é uma roupa que não nos serve mais

( 16 ) Você não sente, não vê

( 17 ) Mas eu não posso deixar de dizer, meu amigo

( 18 ) Que uma nova mudança em breve vai acontecer

( 19 ) O que há algum tempo era novo, jovem

( 20 ) Hoje é antigo

( 21 ) E precisamos todos rejuvenescer

( 19 ) Como Poe, poeta louco americano

( 20 ) Eu pergunto ao passarinho: "Blackbird, o que se faz?"

( 21 ) "Raven never raven never raven"

( 22 ) Blackbird me responde

( 23 ) Tudo já ficou pra trás

( 24 ) "Raven never raven never raven"

( 25 ) Assum-preto me responde

( 26 ) O passado nunca mais

( 27 ) Você não sente, não vê

( 28 ) Mas eu não posso deixar de dizer, meu amigo

( 29 ) Que uma nova mudança

( 30 ) Em breve vai acontecer

( 31 ) O que há algum tempo era novo, jovem

( 32 ) Hoje é antigo

( 33 ) E precisamos todos rejuvenescer

( 34 ) E precisamos rejuvenescer (BELCHIOR, 1976). 
Ao analisarmos a canção, identificamos sete casos de intertextualidade por copresença (duas citações, quatro referências e uma alusão) os quais explicitamos a seguir ${ }^{3}$.

Iniciaremos pelas manifestações explícitas de intertextualidade, no caso duas citações, identificadas nos versos 07 e 08 respectivamente: "Nunca mais teu pai falou: 'She's leaving home' / E meteu o pé na estrada 'like a Rolling Stone".

No verso 7, "Nunca mais teu pai falou: 'She's leaving home", o músico cita o título de uma canção dos Beatles, que também constitui um dos versos dessa canção, e faz a marcação por meio de aspas, o que caracteriza a citação.

Essa canção, She's leaving home, composta por John Lennon e Paul McCartney, foi lançada no álbum Sgt. Pepper's Lonely Hearts Club Band, de 1967, e relata a fuga de uma garota, que sai de casa às cinco da manhã, em busca da liberdade e o desespero dos pais ao constatar o que havia acontecido.

Com a tradução para o português da parte do verso que está em inglês (e que constitui a citação), teríamos o seguinte: Nunca mais teu pai falou: ela está saindo de casa. Sem o conhecimento da canção dos Beatles, só a tradução da citação, recuperaria o sentido do verso. No entanto, para a construção do sentido geral da canção, identificar essa relação intertextual é parte essencial do processo de compreensão do texto, pelo menos em um nível de profundidade e reflexão esperados.
Processo idêntico ocorre no verso 8: "E meteu o pé na estrada 'like a Rolling Stone". Nesse caso, a citação é o título e também trecho de uma música do cantor americano Bob Dylan, lançada em 1965. Essa canção fala de forma sarcástica de uma mulher de alto nível social que, após perder tudo o que possuía, vive na rua sem nenhuma direção como uma pedra rolando. Mas, apesar de tudo, o que se ressalta é como isso é libertador, já que agora que ela não tem mais nada a temer, pode ser ela mesma, já que está invisível para a sociedade.

Na tradução para o português, teríamos: E meteu o pé na estrada como uma pedra rolando. Mais uma vez ressaltamos que só a tradução recuperaria o sentido do verso, mas só o estabelecimento da relação intertextual, com o devido conhecimento da canção citada irá propiciar a construção do sentido geral da canção.

Ainda como manifestações explícitas de intertextualidade, identificamos quatro casos de referências, identificadas nos versos 19, 20, 21 e 25:

( 19 ) Como Poe, poeta louco americano

( 20 ) Eu pergunto ao passarinho: "Blackbird, o que se faz?"

( 21 ) "Raven never raven never raven"

( 22 ) Blackbird me responde

( 23 ) Tudo já ficou pra trás

( 24 ) "Raven never raven never raven"

( 25 ) Assum-preto me responde

( 26 ) O passado nunca mais

De acordo com Piègay-Gros (2010) a referência dá ao leitor uma espécie 
de indicação explícita do que ele deve buscar na sua memória discursiva, pois remete o leitor a um texto mesmo sem citá-lo literalmente. É o que ocorre nos versos destacados acima. Vejamos.

Nos versos 19 e 21, Belchior faz referência ao nome do poeta americano Edgar Allan Poe e ao seu poema The raven (O corvo). No verso 20 , há referência a uma canção dos Beatles, Blackbird. É importante fazer uma ressalva em relação a esses dois últimos versos, já que eles vêm marcados por aspas duplas, o que pode levar o leitor a pensar que se trata de uma citação. No entanto, nesse caso, as aspas são utilizadas para marcar o diálogo que se estabelece entre o múscio e o pássaro, pergunta e resposta, respectivamente: "Eu pergunto ao passarinho: 'Blackbird, o que se faz?' / 'Raven never raven never raven' / Blackbird me responde".

No verso 20, o fragmento que vem aspeado não faz parte do poema $O$ corvo, logo não se caracteriza como uma citação. Belchior diz que, como Poe, ele também pergunta ao pássaro o que fazer. O pássaro, todavia, a quem ele se dirige é o melro (blackbird) e não o corvo, como Poe. Isso, portanto, caracteriza-se como uma referência à canção Blackbird.

Essa canção, Blackbird, foi lançada em 1968 e é considerada um hino à liberdade, já que é um estímulo ao pássaro preto que alce voo, considerando que é esse o seu destino.

$\mathrm{Na}$ sequência, verso 21, o músico retoma o poema $O$ corvo, mas apenas por meio de duas palavras: raven e never, o que constitui outro caso de referência, já que ele não cita os versos de modo literal, mas apenas retoma duas palavras do último verso de cada estrofe do poema em língua inglesa. No poema: "Quoth the Raven, 'Nevermore"; na música: "Raven, never, raven, never, raven, never".

Temos outro caso de referência no verso 25, "Assum-preto me responde", por meio da menção a uma música de Luiz Gonzaga e Humberto Teixeira, Assum Preto, gravada em 1950, e que descreve um pássaro que, embora viva em liberdade, não pode voar porque cegaram seus olhos.

Identificamos apenas uma ocorrência de intertextualidade implícita, no verso 13: "Amor e flor (que é do cartaz?)".

$\mathrm{O}$ verso faz alusão ao movimento hippie, mais precisamente ao Verão do amor, em 1967, um período marcado pelas manifestações contra a guerra do Vietnã, que impulsionou a busca por valores e estilos de vida alternativos dando origem ao movimento hippie. Esse ano, 1967, também ficou conhecido como o Ano da flor. Os hippies utilizavam as flores como um símbolo da ideologia da não violência e de repúdio à guerra do Vietnã, criando o slongan Flowers power (Poder das flores). Eles se intitularam como Flower children (Filhos da flor).

Piègay-Gros (2010) enfatiza que a alusão não se limita só ao campo da intertextualidade, já que o leitor pode ser remetido a elementos ou eventos que não são necessariamente textuais. A primei- 
ra parte do verso, "Amor e flor", não faz alusão a um texto materializado, mas a um movimento de contracultura, iniciado nos anos 1960. Nesse caso, a alusão não se caracteriza como intertextual, mas ao que Cavalcante e Brito (2011) denominou de alusão interdiscursiva que se caracteriza pela remissão à palavra do exterior discursivo.

Já a segunda parte do verso, "(que é do cartaz)", alude a um texto efetivamente produzido, um cartaz, o que caracteriza a alusão intertextual. Durante o Verão do amor, foi organizado o primeiro grande festival de música regido pelos ideais da contracultura: o Monterey Pop Festival, idealizado por pessoas ligadas ao movimento hippie, na Califórnia. A seguir, o célebre cartaz do Festival:

Figura 1 - Cartaz do Festival Monterey Pop Festival

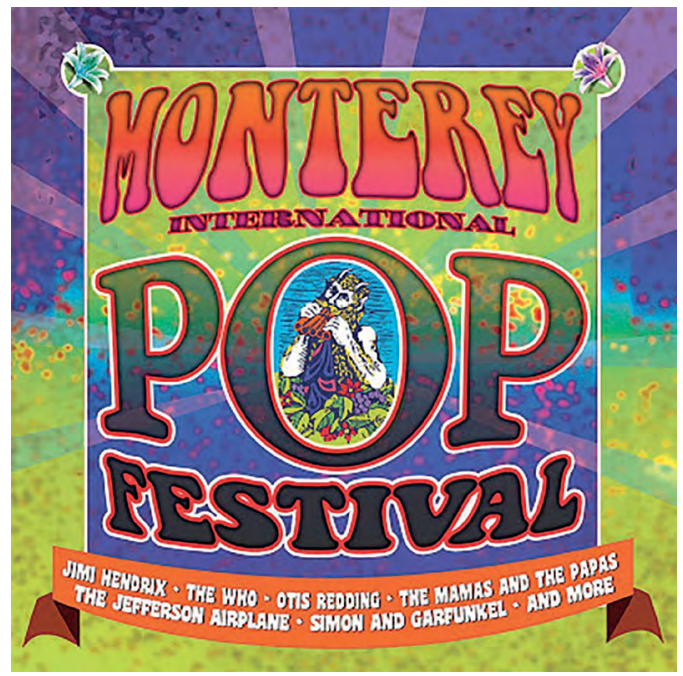

Fonte: We wanna rock you (2012, não paginado).
Belchior apenas menciona as palavras amor e flor e cartaz, cabendo ao ouvinte/leitor, acionar o seu conhecimento prévio sobre esses elementos. Sem a identificação do intertexto, haveria dificuldade de compreenão do sentido do verso, mesmo que fosse possível recuperá-lo pelo contexto da canção. Sem o conhecimento prévio do que representou o movimento hippie e de alguns dos elementos que lhe deram identidade, a construção do sentido ficaria incompleta.

Além dessas informações, o conhecimento das condições de produção da canção ajuda a compreender melhor as relações intertextuais encontradas. Vejamos.

Essa canção foi lançada em 1976, uma época marcada pela repressão da ditadura militar. O título, Velha roupa colorida, remete às roupas coloridas adotadas pelo movimento hippie, símbolo da liberdade, para, em seguida, dizer que essas roupas (o passado) já não servem, pois ficaram velhas diante do momento repressivo pelo qual o país e parte da América Latina estava passando. Vejamos o que afirmam Mateus Kuroda e Mônica Santos a esse respeito:

\footnotetext{
Nesse período o mundo começava a ver, com seus próprios olhos, a devastação que veio acompanhada com o domínio e a sobreposição dos pensamentos conservadores em relação às ideias democráticas. Grande parte da população da América Latina estava submetida à política de extrema direita, vivendo sob o regime de ditaduras de cunho militar, que usavam técnicas quase desumanas para conter a população (KURODA; SANTOS, 2014, p. 74).
} 
Isso ajuda a entender o discurso libertário presente em toda a canção, inclusive e principalmente nas ocorrências intertextuais identificadas, já que todas as canções citadas abordam explícita ou implicitamente essa temática.

No entanto, dado o ambiente de censura que predominava, o músico teve que recorrer ao recurso da intertextualidade para expor o seu protesto. Isso é que explica Kuroda e Santos, ao afirmarem que

[...] o recurso mais utilizado como manifestação política e ideológica foi a música, pois seu caráter polissêmico e o seu jogo entre explícito e implícito enganava a elite militar; passando, pois, pelo crivo da censura (2014, p. 73).

Para falar do período negro (em oposição às velhas roupas coloridas), o músico fala de três pássaros pretos: o melro (blackbird), o corvo (raven) e o assum preto. Sendo os pássaros símbolos da liberdade, ele os evoca para falar da falta dessa, mas não se deixa contagiar pelo pessimismo, ao concluir com os versos: "Mas eu não posso deixar de dizer, meu amigo / Que uma nova mudança / Em breve vai acontecer".

\section{Considerações finais}

Embora tenhamos analisado aqui apenas a canção Velha roupa colorida, é possível perceber, na discografia de Belchior, que a intertextualidade é uma característica da sua obra musical. $\mathrm{O}$ autor constrói suas canções sempre em diálogo com outras canções e grandes obras e autores da literatura brasileira e universal. Nessa canção, objeto de nosso estudo, isso se evidencia, de fato, já que encontramos sete tipos de ocorrências intertextuais por copresença.

Através do estudo da intertextualidade, definido por Genettte (2010) e ampliado por Piègay-Gros (2010) e Cavalcante e Brito (2011), percebemos como o reconhecimento das marcas intertextuais são importantes para a apropriação do texto por parte do leitor. Essa apropriação será maior, quanto maior for o grau de sentido atribuído pelo leitor/ ouvinte ao texto lido/escutado.

Esperamos, pois, ter demonstrado a importância da compreensão da participação das manifestações intertextuais nos sentidos dos enunciados, posto que, sem a consideração delas, muitas vezes, como no caso da canção Velha roupa colorida, ficam perdidos elementos fundamentais para a construção de sentido do texto.

\section{Intertextual markers in Belchior's song Velha roupa colorida}

\begin{abstract}
This study aims at analyzing the intertextual markers in Belchior's song Velha Roupa Colorida, at demonstrating how such intertextuality shows itself by the relations of co-presence and how the recognition of these intertextual occurrences contribute to the reader's and listener's understanding of the text. The theoretical background is based on Genette (2010), Piègay-Gros (2010) and Cavalcante
\end{abstract}


and Brito (2011), as well as on Koch, Bentes and Cavalcante (2012), Koch (2014) and Costa (2012) perspective. Intertextuality is so present in most of Belchior's songs that it can be considered one of his characteristics. However, given the scope of this study, we focused on only one song which satisfies properly the aims of this paper. We concluded that intertextual occurrences such as citations, references and allusion, contribute enormously to the meaning of the song under analysis.

Keywords: Intertextuality. Meaning Construction. Song. Belchior.

\section{Notas}

1 Consideramos estratégias de construção de sentidos dos textos, além da intertextualidade, os processos referenciais, os recursos multimodais, os hipertextuais e as sequências discursivas.

2 Regime instaurado em $1^{\circ}$ de abril de 1964 e que durou até 15 de março de 1985 , sob comando de sucessivos governos militares. De caráter autoritário e nacionalista, teve início com o golpe militar que derrubou o governo de João Goulart, o então presidente democraticamente eleito.

3 Para facilitar a localização dessas ocorrências intertextuais na canção, utilizamos números cardinais de 01 a 34 e as destacamos em negrito.

\section{Referências}

ALBIN, R. C. Dicionário Cravo Albin da Música Popular Brasileira. Rio de Janeiro: Instituto Cultural Cravo Albin, 2002. Disponível em: <http://cravoalbin.ibest.com.br>. Acesso em: 20 jul. 2016.

BAKHTIN, M. M. Estética da criação verbal. Tradução de Paulo Bezerra. 4. ed. São Paulo: Martins Fontes, 2003.
BAKHTIN, M. M. (VOLOCHÍNOV, V. N.). Marxismo e filosofia da linguagem: problemas fundamentais do método sociológico na ciência da linguagem. 9. ed. Tradução de M. Lahud e Y. F. Vieira. São Paulo: Hucitec, 2004.

BALZAC, H. de. Uma paixão no deserto. São Paulo: Clube do Livro, 1976.

BAZERMAN, C. Gênero, agência e escrita. Tradução de Ângela P. Dionísio e Judith C. Hoffnag. 2. ed. São Paulo: Cortez, 2011.

CAVALCANTE, M. M.; BRITO, M. A. P. Intertextualidades, heterogeneidades e referenciação. Linha d'Água, São Paulo, v. 24, n. 2, p. 259-276, 2011.

CHARAUDEAU, P.; MAINGUENEAU, D. Dicionário de Análise do Discurso. Coordenação da tradução Fabiana Komesu. 2. ed. São Paulo: Contexto, 2008.

COSTA, N. B. da. Música popular, linguagem e sociedade (Analisando o discurso literomusical brasileiro). Curitiba: Appris, 2012.

GENETTE, G. Palimpsestes: a literatura de segunda mão. Tradução de Cibele Braga et al. Belo Horizonte: Edições Viva Voz, 2010.

KOCH, I. G. V. O texto e a construção dos sentidos. 10. ed. São Paulo: Contexto, 2014.

KOCH, I. G. V.; BENTES, A. C.; CAVALCANTE, M. M. Intertextualidade: diálogos possíveis. 3. ed. São Paulo: Cortez, 2012.

KRISTEVA, J. Introdução à semanálise. São Paulo: Perspectiva, 1974.

KURODA, M. S. B.; SANTOS, M. M. dos. Música em (dis)curso: uma análise do eixo vertical. Revista Philologus, Rio de janeiro, a. 20, n. 59, p. 69-82, maio/ago. 2014.

MEIRELES, C. Poesia completa. Rio de Janeiro: Nova Aguilar, 1994.

PAULINO, G.; WALTY I.; CURY, M. Z. Intertextualidade teoria e prática. 2. ed. Belo Horizonte: Editora Lê, 1995. 
PIÈGAY-GROS, N. Introduction à l'intertextualité. Tradução de Mônica Magalhães Cavalcante, Mônica Maria Feitosa Braga Gentil e Vicência Maria Freitas Jaguaribe. Intersecções, Jundiaí, a. 3, n. 1, p. 220-244, abr. 2010.

PLATÃo. A República. Tradução de Maria Helena da Rocha Pereira. 2. ed. Lisboa: Caloustre Gulbenkian, 1993.

QUINTANA, M. Caderno H. Porto Alegre: Globo, 1973.

VAN DIJK, T. A. Discourse and context: a sociocognitive approach. New York: Cambridge University Press, 2008.

WE WANNA ROCK YOU. Os grandes festivais de Heavy Metal (Parte I). 2012. Disponível em: <http://wewannarockyou.blogspot. com.br/2012/04/os-grandes-festivais-de-heavy-metal.html>. Acesso em: 7 jun. 2017.

\section{Discografia}

BEATLES. The Beatles. Londres: Aplle Records, 1968. 1 LP.

BEATLES. Sgt. Pepper's Lonely Hearts Club Band. Londres: Parlophone, 1967. 1 LP.

BELCHIOR, A. C. G. Bahiuno. São Paulo: MoviePlay, 1993. 1 CD.

BELCHIOR, A. C. G. Era uma vez um homem e seu tempo. Rio de janeiro: Warner, 1979. 1 LP.

BELCHIOR, A. C. G. Alucinação. Rio de janeiro: Polygram/Philips, 1976. 1 LP.

BELCHIOR, A. C. G. Belchior a palo seco. São Paulo: Continental, 1974. 1 LP.

DYLAN, B. Like a Rolling Stone / Gates of Eden. Washington: Columbia Records, 1965. 1 LP.

GONZAGA, L. Sanfona do povo. Rio de Janeiro: RCA, 1964. 1 LP.

VELOSO, C. Caetano. Rio de janeiro: Philips, 1987. $1 \mathrm{LP}$. 